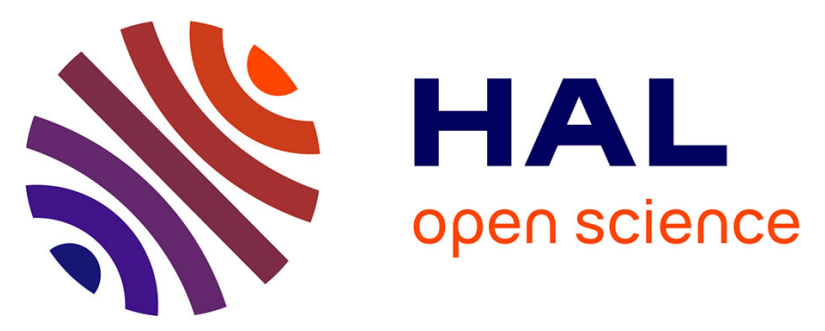

\title{
Analog modulation of spike-evoked transmission in CA3 circuits is determined by axonal Kv1.1 channels in a time-dependent manner
}

Andrzej Bialowas, Sylvain Rama, Mickael Zbili, Vincenzo Marra, Laure

Fronzaroli-Molinieres, Norbert Ankri, Edmond Carlier, Dominique Debanne

\section{To cite this version:}

Andrzej Bialowas, Sylvain Rama, Mickael Zbili, Vincenzo Marra, Laure Fronzaroli-Molinieres, et al.. Analog modulation of spike-evoked transmission in CA3 circuits is determined by axonal Kv1.1 channels in a time-dependent manner. European Journal of Neuroscience, 2015, 41 (3), pp.293-304. 10.1111/ejn.12787 . hal-01766833

\section{HAL Id: hal-01766833 \\ https://hal-amu.archives-ouvertes.fr/hal-01766833}

Submitted on 25 Apr 2018

HAL is a multi-disciplinary open access archive for the deposit and dissemination of scientific research documents, whether they are published or not. The documents may come from teaching and research institutions in France or abroad, or from public or private research centers.
L'archive ouverte pluridisciplinaire HAL, est destinée au dépôt et à la diffusion de documents scientifiques de niveau recherche, publiés ou non, émanant des établissements d'enseignement et de recherche français ou étrangers, des laboratoires publics ou privés. 


\title{
Analog modulation of spike-evoked transmission in CA3 circuits is determined by axonal Kv1.1 channels in a time-dependent manner
}

\author{
Andrzej Bialowas, ${ }^{1,2}$ Sylvain Rama, ${ }^{1,2}$ Mickaël Zbili, ${ }^{1,2}$ Vincenzo Marra, ${ }^{1,2}$ Laure Fronzaroli-Molinieres, ${ }^{1,2}$ \\ Norbert Ankri, ${ }^{1,2}$ Edmond Carlier $^{1,2}$ and Dominique Debanne ${ }^{1,2}$ \\ ${ }^{1}$ INSERM, UMR_S 1072 Marseille, France \\ ${ }^{2}$ Aix-Marseille Université, UNIS, Marseille, France
}

Keywords: axon terminal, potassium channels, rat, synaptic plasticity

\begin{abstract}
Synaptic transmission usually depends on action potentials (APs) in an all-or-none (digital) fashion. Recent studies indicate, however, that subthreshold presynaptic depolarization may facilitate spike-evoked transmission, thus creating an analog modulation of spike-evoked synaptic transmission, also called analog-digital (AD) synaptic facilitation. Yet, the underlying mechanisms behind this facilitation remain unclear. We show here that AD facilitation at rat CA3-CA3 synapses is time-dependent and requires long presynaptic depolarization (5-10 s) for its induction. This depolarization-induced AD facilitation (d-ADF) is blocked by the specific Kv1.1 channel blocker dendrotoxin-K. Using fast voltage-imaging of the axon, we show that somatic depolarization used for induction of d-ADF broadened the AP in the axon through inactivation of Kv1.1 channels. Somatic depolarization enhanced spikeevoked calcium signals in presynaptic terminals, but not basal calcium. In conclusion, axonal Kv1.1 channels determine glutamate release in CA3 neurons in a time-dependent manner through the control of the presynaptic spike waveform.
\end{abstract}

\section{Introduction}

In most central nervous system (CNS) neurons, information is generally conveyed to the postsynaptic cell through spike-evoked packets of neurotransmitter. This all-or-none or digital mode of neuronal signaling is, however, modulated by subthreshold analog activity in the presynaptic element. Hybrid analog-digital (AD) enhancement of synaptic transmission, initially described in invertebrates (Shimahara \& Tauc, 1975; Nicholls \& Wallace, 1978; Shimahara \& Peretz, 1978; Shapiro et al., 1980), has been reported more recently in mammalian CNS synapses including cortical (Shu et al., 2006; Kole et al., 2007; Zhu et al., 2011), cerebellar (Bouhours et al., 2011; Christie et al., 2011) and hippocampal synapses (Alle \& Geiger, 2006; Scott et al., 2008). This facilitation is induced by depolarization of the presynaptic neuron and is mediated by an elevation of glutamate release (Awatramani et al., 2005; Kole et al., 2007; Bouhours et al., 2011).

Two mechanisms have been reported to account for AD facilitation of synaptic strength induced by depolarization in central neurons. Depolarization of the somatic region of the presynaptic neuron may enhance synaptic transmission as the consequence of voltagedependent inactivation of $\mathrm{K}^{+}$channels (Kole et al., 2007; Shu et al.,

Correspondence: Dr D. Debanne, ${ }^{2}$ Aix-Marseille Université, as above.

E-mail: dominique.debanne@univ-amu.fr

A.B. and S.R. contributed equally to this work. 2007a,b). Synaptic transmission can also be facilitated by analog depolarization of the soma as the consequence of the elevation in basal $\mathrm{Ca}^{2+}$ concentration mediated by the opening of P/Q-type voltage-gated $\mathrm{Ca}^{2+}$ channels (Awatramani et al., 2005; Bouhours et al., 2011; Christie et al., 2011). Subthreshold depolarization of the cell body causes a $\mathrm{Ca}^{2+}$ rise in axons of $\mathrm{L} 5$ pyramidal neurons ( $\mathrm{Yu}$ et al., 2010), but its role on release remains to be determined.

Facilitation of synaptic transmission induced by presynaptic depolarization has been reported in the hippocampus (Saviane et al., 2003; Alle \& Geiger, 2006; Sasaki et al., 2012), but the underlying mechanisms of this facilitation are not fully understood (Debanne et al., 2013). In CA3 neurons, AD facilitation has been shown to result from spike enlargement in the axon and to be blocked by 4-aminopyridine (Sasaki et al., 2012), but the identity of the $\mathrm{Kv}$ channel subunits has not been determined. In addition, it is not clear whether spike broadening in CA3 neurons is purely voltage-dependent or whether it is also time-dependent (Sasaki et al., 2012). Finally, the role of basal $\mathrm{Ca}^{2+}$ elevation in depolarization-induced facilitation is still undefined in $\mathrm{Kv}$-dependent $\mathrm{AD}$ facilitation $\mathrm{Yu}$ et al., 2010; Sasaki et al., 2012). We therefore examined these issues in CA3 neurons. We show here that depolarization-induced $\mathrm{AD}$ facilitation (d-ADF) in CA3-CA3 connections is time-dependent and occurs when the presynaptic action potential (AP) is triggered from a long ( $>5 \mathrm{~s})$ near-threshold depolarization of the presynaptic neuron. d-ADF was blocked by the selective Kv1.1 channel blocker dendrotoxin-K. Subthreshold somatic depolarization that induces d-ADF was found to enhance spike-evoked calcium signals in 
presynaptic terminals, but not basal calcium. In conclusion, our study shows that physiological modulation of presynaptic spike width by axonal Kv1.1 channels is a major determinant of glutamate release in CA3 neurons, thus showing that the informational content of spikes is activity-dependent.

\section{Materials and methods}

\section{Organotypic cultures of rat hippocampus}

Hippocampal slice cultures were prepared as described previously (Debanne et al., 2008). All experiments were carried out according to the European and Institutional guidelines for the care and use of laboratory animals (Council Directive 86/609/EEC and French National Research Council) and the protocol was approved by the Veterinary Services of the Bouches-du-Rhône prefecture (agreement 13.145 to D.D.). Briefly, postnatal day 7-8 Wistar rats were deeply anesthetized by intraperitoneal injection of chloral hydrate, the brain removed and each hippocampus individually dissected. Hippocampal slices $(350 \mu \mathrm{m})$ were placed on 20-mm latex membranes (Millicell; Millipore, Saint-Quentin en Yvelines, France) inserted into 35-mm Petri dishes containing $1 \mathrm{~mL}$ of culture medium and maintained for up to 30 days in an incubator at $34{ }^{\circ} \mathrm{C}, 95 \% \mathrm{O}_{2}-5 \% \mathrm{CO}_{2}$. The culture medium contained (in $\mathrm{mL}$ ) 25 minimal essential medium, 12.5 Hanks' balanced saline solution, 12.5 horse serum, 0.5 penicillin/ streptomycin, 0.8 glucose $(1 \mathrm{M}), 0.1$ ascorbic acid $(1 \mathrm{mg} / \mathrm{mL}), 0.4$ HEPES ( $1 \mathrm{~m}), 0.5 \mathrm{~B} 27$ and 8.95 sterile $\mathrm{H}_{2} \mathrm{O}$. To limit glial proliferation, $5 \mu \mathrm{M}$ cytosine-arabinoside (Ara-C) was added to the culture medium starting at 4 days in vitro (DIV) (Seil et al., 1992).

\section{Electrophysiological recordings and data analysis}

Dual whole-cell recordings were obtained from pairs of CA3 neurons as detailed previously (Boudkkazi et al., 2007; Debanne et al., 2008). The external solution contained (mM) $125 \mathrm{NaCl}, 26 \mathrm{NaH}-$ $\mathrm{CO}_{3}, 3 \mathrm{CaCl}_{2}, 2.5 \mathrm{KCl}, 2 \mathrm{MgCl}_{2}, 0.8 \mathrm{NaH}_{2} \mathrm{PO}_{4}$ and 10 D-glucose, and was equilibrated with $95 \% \quad \mathrm{O}_{2}-5 \% \quad \mathrm{CO}_{2}$. Patch pipettes (5-10 $\mathrm{M} \Omega$ ) were filled with a solution containing (in $\mathrm{mM}$ ): 120 potassium gluconate, $20 \mathrm{KCl}, 10 \mathrm{HEPES}, 0.5 \mathrm{EGTA} ; 2 \mathrm{MgCl}_{2}, 2$ $\mathrm{Na}_{2} \mathrm{ATP}$ and $0.3 \mathrm{NaGTP}$ ( $\mathrm{pH}$ 7.4). All recordings were made at $29{ }^{\circ} \mathrm{C}$ in a temperature-controlled recording chamber (Luigs \& Neumann, Ratingen, Germany). Classically, the presynaptic neuron was recorded in current-clamp mode with an Axoclamp 2B amplifier (Axon Instruments, Molecular Devices, Sunnyvale, CA, USA) and the post-synaptic cell in voltage-clamp mode with an Axopatch 200B amplifier (Axon Instruments, Molecular Devices). Pre- and post-synaptic cells were held at their resting membrane potential $(\sim-65 \mathrm{mV})$. Presynaptic APs were generated by injecting brief $(5 \mathrm{~ms})$ depolarizing pulses of current at a frequency of $0.1 \mathrm{~Hz}$. Short-term facilitation was assessed with two presynaptic stimulations delivered at a frequency of $20 \mathrm{~Hz}$. In a few experiments, EGTA $(10 \mathrm{~mm})$ was added to the internal pipette solution. To allow diffusion of EGTA from the pipette to the presynaptic terminal, data collection started $10-15$ min after breaking in. In this case the recordings typically lasted $40-50 \mathrm{~min}$ to test d-ADF.

The voltage and current signals were low-pass filtered $(3 \mathrm{kHz})$, and acquisition of 500-ms sequences was performed at $10-20 \mathrm{kHz}$ with Acquis1 (G. Sadoc, CNRS, Gif-sur-Yvette, France) or pClamp (Axon Instruments) version 8, 9 or 10. Data were analysed with ClampFit (Axon Instruments) or Detectivent 4.0 (N. Ankri, INSERM U1072, Marseille, France). Synaptic responses were averaged following alignment of the presynaptic APs using automatic peak detection. All responses including failures were averaged, and thus changes in synaptic efficacy are reported here. Pooled data are presented as mean \pm standard error (SE) and statistical analysis was performed using the Mann-Whitney $U$-test or Wilcoxon rank-signed test.

Drugs were bath applied. DTx-I was obtained from Latoxan (Valence, France), DTx-K from Sigma (St Louis, MO, USA) and $\omega$-agatoxin IVa from Tocris (Bristol, UK). The toxins were directly applied in the recording chamber after interruption of the circulation system for $2 \mathrm{~min}$.

\section{Calcium and sodium imaging}

All recordings were obtained from CA3 pyramidal neurons in the whole-cell configuration at $31^{\circ} \mathrm{C}$. Imaging experiments were performed on an LSM710 confocal system (Zeiss, Oberkochen, Germany). Depending on calcium imaging experiments we added $50 \mu \mathrm{M}$ Alexa-594 and $250 \mu \mathrm{M}$ Fluo-4 (Invitrogen, Carlsbad, CA, USA) or $200 \mu \mathrm{M}$ Oregon Green 488 BAPTA-1 (OGB-1; Invitrogen) to the pipette solution. Fluo- 4 is faster than OGB-1 but the affinity of OGB-1 is higher. We therefore used both dyes in our experiments to detect fast signals as being those produced by APs (principally measured with Fluo-4) and very small signals as those produced by sub-threshold depolarization (principally measured with OGB-1). For $\mathrm{Na}^{+}$imaging experiments, $50 \mu \mathrm{M}$ Alexa-594 and $500 \mu \mathrm{M}$ CoroNa Green (Invitrogen) were added.

Fluorescence excitation was performed with laser sources at $488 \mathrm{~nm}$ for Fluo-4, OGB-1 or CoroNa Green and $543 \mathrm{~nm}$ for Alexa-594. Emitted fluorescence was collected between 500 and $580 \mathrm{~nm}$ for Fluo-4 and CoroNa Green, 620 and $750 \mathrm{~nm}$ for Alexa594, and 500 and $650 \mathrm{~nm}$ for OGB-1. After whole-cell access, the dyes were allowed to diffuse for $15-20 \mathrm{~min}$ before performing experiments. APs were typically induced by short $(5-10 \mathrm{~ms})$ pulses of depolarizing current (900-1400 pA) in current clamp mode and synchronized with calcium imaging in line-scan mode. Line-scan speed was set to $0.5-2 \mathrm{kHz}$ depending on experiments.

For CoroNa Green experiments, a stronger depolarizing current was used (300-400 pA) for $1 \mathrm{~s}$ to induce trains of APs in the cell, synchronized with sodium imaging in line-scan mode.

In Fluo-4 experiments or CoroNa Green experiments, Alexa-594 fluorescence was used to reveal neuronal morphology. Fluorescence signals emitted by Fluo-4 and CoroNa Green were used for calcium and sodium imaging, respectively. In OGB-1 experiments, Oregon fluorescence was used for both morphology and $\mathrm{Ca}^{2+}$ imaging.

After acquisition, Fluo-4 or OGB-1 fluorescence was converted to $\Delta F / F$ values. Peak amplitude and decay time of $\mathrm{Ca}^{2+}$ influx were calculated with a custom-written analysis program written in Labview (National Instruments, Austin, TX, USA).

The axon was identified by visual cues: a long, thin, aspiny process with constant diameter, emerging from the soma or from a primary dendrite near the cell body. The axon was followed until the first bulges of the membrane, revealing presynaptic boutons. Putative en passant boutons were identified as varicosities on axon collaterals with a maximal diameter and length of $\sim 1-2 \mu \mathrm{m}$ (Shepherd et al., 2002).

\section{Voltage imaging of the axon}

CA3 pyramidal neurons were loaded with JPW3028 (250 $\mu \mathrm{M})$ following a protocol detailed by Foust et al. (2011). JPW3028 was a gift of Dr L. M. Loew (University of Connecticut Health Center, Farmington, CT, USA). In practice, the tip of the electrode was 
pre-filled with Alexa-488 $(50 \mu \mathrm{M})$ to visualize the morphology of the neuron and back-filled with the voltage-sensitive dye JPW-3028 $(250 \mu \mathrm{M})$. After $5 \mathrm{~min}$ of whole-cell recording, Alexa diffused in the neuron and the neuronal morphology was acquired with the LSM-710 confocal microscope. If the neuron displayed a clearly visible axon and axon initial segment (AIS), the protocol was continued (otherwise the cell was discarded). The AIS was defined as the proximal segment of the axon extending up to $60 \mu \mathrm{m}$ from the axon hillock in CA3 pyramidal neurons (Meeks \& Mennerick, 2007). The cell was recorded in whole-cell mode for at least $15 \mathrm{~min}$ to obtain sufficient diffusion of the dye into the axon, and the imaging protocol was then started. The cell was illuminated in wide field with a 525-nm LED system (CoolLed; Roper Scientific/Photometrics, Tucson, AZ, USA) via a $60 \times 1.0$ N.A. water-immersion objective (Zeiss). Collected fluorescence was long-pass filtered at $610 \mathrm{~nm}$ and projected onto a $128 \times 128$-pixel high-speed EMCCD camera (Evolve 128; Photometrics) with a maximum frame rate of $7 \mathrm{kHz}$. In a typical trial, we induced APs in the soma by injecting a 5- to 10-ms current pulse, synchronized with LED illumination and camera acquisition at $2 \mathrm{kHz}$ for $40 \mathrm{~ms}$. To improve the signal-to-noise ratio, we acquired 50-100 sweeps sequentially, aligned the CCD signal according to the AP jitter recorded by patch-clamp and averaged the corresponding sweeps. Bleaching was removed by subtracting an exponential function fit to portions of the fluorescence signal containing no spikes. All these operations were performed using ad hoc analysis software written in LabView (National Instruments).

\section{Recordings from the axon}

Simultaneous recordings were obtained from the soma in whole-cell configuration and the axon in cell-attached configuration (Boudkkazi et al., 2011). Briefly, the axon was recorded 10-15 min after whole-cell access of the somatic compartment and complete labeling of the axon by Alexa 488. The axon was visualized with the LSM710 confocal microscope and negative pressure was applied to the pipette to obtain a high-resistance seal on the axon. Occasionally, a short length of the axon was pulled into the lumen of the patch pipette. To obtain cell-attached recording, a brief suction was applied to the pipette. In these conditions, the spike measured in the axon had a positive polarity (amplitude $0.3-1.2 \mathrm{mV}$ ).

\section{Modeling}

A multi-compartment model of a CA3 pyramidal neuron was simulated with NEURON 7.2 (http://www.neuron.yale.edu/neuron/download). The diameter and length of each compartment are provided in Table 1. The passive electrical properties $C_{\mathrm{m}}$ and $R_{\mathrm{i}}$ were set to $1 \mu \mathrm{F} / \mathrm{cm}^{2}$ and $100 \Omega \mathrm{cm}$, respectively, uniformly throughout all compartments (Major et al., 1994). All simulations were run with $10-\mu \mathrm{s}$ time steps and the nominal temperature of simulations was $28^{\circ} \mathrm{C}$. The voltage-dependence of activation and inactivation of a HodgkinHuxley-based conductance model $\left(g_{\mathrm{NaSoma}}, g_{\mathrm{NaAxon}}, g_{\mathrm{KDR}}, g_{\mathrm{Kv} 1.1}\right.$, $\left.g_{\mathrm{Ca}}\right)$ are given as follows:

$$
\begin{aligned}
& g_{\text {NaSoma }}=G_{\mathrm{NaSoma}} * m^{3} \text { Soma } * h_{\text {Soma }} \\
& g_{\text {NaAxon }}=G_{\text {NaAxon }} * m^{3} \text { Axon } * h_{\text {Axon }} \\
& g_{\text {KDR }}=G_{\mathrm{KDR}} * n \\
& g_{\mathrm{Kv} 1.1}=G_{\mathrm{Kv1}} * p^{*} k \\
& g_{\mathrm{CaP} / \mathrm{Q}}=G_{\mathrm{CaP} / \mathrm{Q}} * r
\end{aligned}
$$

where $m_{\text {Soma }}, m_{\text {Axon }}, n, p$ and $r$ are dynamic activation variables, and $h_{\text {Soma }}, h_{\text {Axon }}$ and $k$ are dynamic inactivation variables. They evolve according to the following differential equations [adapted

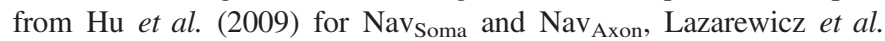
(2002) for $K_{\mathrm{DR}}$, Yang et al. (2013) for $\mathrm{K}_{\mathrm{v}} 1.1$ and Bischofberger et al. (2002) for $\mathrm{CaP} / \mathrm{Q}]$ :

$$
\begin{aligned}
\frac{\mathrm{d} m_{\text {Soma }}}{\mathrm{d} t} & =\frac{m_{\infty \text { Soma }}-m}{m_{\zeta \text { Soma }}} \\
\frac{\mathrm{d} h_{\text {Soma }}}{\mathrm{d} t} & =\frac{h_{\infty \text { Soma }}-h}{h_{\zeta \text { Soma }}} \\
\frac{\mathrm{d} m_{\text {Axon }}}{\mathrm{d} t} & =\frac{m_{\infty \text { Axon }}-m}{m_{\zeta \text { Axon }}} \\
\frac{\mathrm{d} h_{\text {Axon }}}{\mathrm{d} t} & =\frac{h_{\infty \text { Axon }}-h}{h_{\zeta \text { Axon }}} \\
\frac{\mathrm{d} n}{\mathrm{~d} t} & =\frac{n_{\infty}-n}{n_{\zeta}}
\end{aligned}
$$$$
m_{\infty \text { Soma }}=\frac{1}{1+\mathrm{e}^{(0.17 *(-29.7-V))}}
$$$$
h_{\infty \text { Soma }}=\frac{1}{1+\mathrm{e}^{(-0.14 *(-67-V))}}
$$$$
m_{\infty \mathrm{Axon}}=\frac{1}{1+\mathrm{e}^{(0.17 *(-43.9-V))}}
$$$$
h_{\infty \mathrm{Axon}}=\frac{1}{1+\mathrm{e}^{(-0.18 *(-80-V))}}
$$$$
m_{\zeta \text { Soma }}=\frac{1}{\frac{\mathbf{0 . 1 8 2} *(\boldsymbol{V}+\mathbf{4 3})}{1-\mathrm{e}^{-(V+43) / 6}}-\frac{\mathbf{0 . 1 2 4} *(\boldsymbol{V}+\mathbf{4 3})}{1-\mathrm{e}^{-(V+43) / 6}}}
$$$$
h_{\zeta \text { Soma }}=\frac{1}{\frac{\mathbf{0 . 0 2 4} *(\boldsymbol{V}+\mathbf{5 0})}{1-\mathrm{e}^{-(V+50) / 5}}-\frac{\mathbf{0 . 0 0 9 1}(\boldsymbol{V}+\mathbf{7 5})}{1-\mathrm{e}^{-(V+75) / 5}}}
$$$$
m_{\zeta \text { Axon }}=\frac{1}{\frac{\mathbf{0 . 1 8 2} *(\boldsymbol{V}+\mathbf{4 3})}{1-\mathrm{e}^{-(V+43) / 6}}-\frac{\mathbf{0 . 1 2 4} *(\boldsymbol{V}+\mathbf{4 3})}{1-\mathrm{e}^{-(V+43) / 6}}}
$$$$
h_{\zeta \text { Axon }}=\frac{1}{\frac{\mathbf{0 . 0 2 4} *(\boldsymbol{V}+\mathbf{5 0})}{1-\mathrm{e}^{-(V+50) / 5}}-\frac{\mathbf{0 . 0 0 9 1} *(\boldsymbol{V}+\mathbf{7 5})}{1-\mathrm{e}^{-(V+75) / 5}}}
$$

$$
n_{\infty}=\frac{1}{1+\mathrm{e}^{(0.114 *(13-V))}}
$$$$
n_{\zeta}=\frac{\mathrm{e}^{-(V-13) / 12.2}}{\left(1+\mathrm{e}^{-(V-13) / 8.55}\right) * 0.02}
$$ 

$\frac{\mathrm{d} p}{\mathrm{~d} t}=\frac{p_{\infty}-p}{p_{\zeta}}$
$p_{\infty}=\frac{1}{1+\mathrm{e}^{(0.07 *(-17.5-V))}}$
$p_{\zeta}=2$
$\frac{\mathrm{d} k}{\mathrm{~d} t}=\frac{k_{\infty}-k}{k_{\zeta}}$
$k_{\infty}=\frac{1}{1+\mathrm{e}^{(-0.18 *(-72.7-V))}}$
$k_{\zeta}=2000$
$\frac{\mathrm{d} r}{\mathrm{~d} t}=\frac{r_{\infty}-r}{r_{\zeta}}$
$r_{\infty}=\frac{1}{1+\mathrm{e}^{(0.14 *(-3.9-V))}}$
$r_{\zeta}=\frac{1}{1.2 * \mathrm{e}^{V / 31.5}-1.14 * \mathrm{e}^{-V / 8.6}}$

TABle 1. Model parameters

\begin{tabular}{llll}
\hline & Soma & Axon & Terminal \\
\hline Length $(\mu \mathrm{m})$ & 30 & 200 & 2 \\
$\begin{array}{l}\text { Diameter }(\mu \mathrm{m}) \\
\begin{array}{l}\text { Membrane capacitance } \\
(\mu \mathrm{F} / \mathrm{cm})\end{array}\end{array}$ & 1 & 1 & 2 \\
$\begin{array}{l}\text { Passive conductance } \\
\quad\left(\mathrm{S} / \mathrm{cm}^{2}\right)\end{array}$ & $5 \times 10^{-5}$ & $5 \times 10^{-5}$ & $5 \times 10^{-5}$ \\
$I_{\text {Nasoma }}\left(\mathrm{S} / \mathrm{cm}^{2}\right)$ & 0.05 & 0 & \\
$I_{\text {Naaxon }}\left(\mathrm{S} / \mathrm{cm}^{2}\right)$ & 0 & 0.12 & 0 \\
$I_{\mathrm{D}}$ & 0 & 0.008 & 0.12 \\
$I_{\mathrm{KDR}}\left(\mathrm{S} / \mathrm{cm}^{2}\right)$ & 0.01 & 0.001 & 0.008 \\
$I_{\mathrm{Ca}}\left(\mathrm{S} / \mathrm{cm}^{2}\right)$ & 0 & 0 & 0.0015 \\
\hline
\end{tabular}

where $V$ is the membrane potential of the simulated neuron. The equilibrium potential for $\mathrm{Na}^{+}, \mathrm{K}^{+}, \mathrm{Ca}^{2+}$ and passive channels was set to $+50,-77,+75$ and $-65 \mathrm{mV}$, respectively. The conductance density for each compartment was based on experimental work (Bischofberger et al., 2002; Hu et al., 2009; Kim et al., 2012) and is provided in Table 1. Two neurons were generated with these conductance parameters and were connected through a synapse model (Destexhe et al., 1994). AP and calcium currents were recorded in the presynaptic terminal and the synaptic potential in the post-synaptic cell (excitatory post-synaptic potential, EPSP).

The resting membrane potential in the soma of the presynaptic neuron was set to $-70 \mathrm{mV}$ in control conditions and $-55 \mathrm{mV}$ for the depolarized state. These variations in somatic resting membrane potential propagated along the axon with a space constant of $435 \mu \mathrm{m}$.

\section{Results}

\section{$d-A D F$ in $C A 3$ neurons}

Pairs of connected CA3 pyramidal neurons were recorded in organotypic slice cultures of the hippocampus and the incidence of changes in membrane potential of the presynaptic neuron was determined at CA3-CA3 excitatory synapses. Synaptic responses were evoked when the presynaptic cell was either held at constant hyperpolarized $(-75 /-80 \mathrm{mV})$ or depolarized $(-45 /-50 \mathrm{mV})$ potential. Synaptic transmission was enhanced when the presynaptic spike was elicited from a constant depolarization of the membrane potential (Fig. 1A). d-ADF was quantified by normalizing postsynaptic responses obtained at depolarized potential $(-48 \pm 1 \mathrm{mV}, n=13)$ to those measured at hyperpolarized potential $(-77 \pm 1 \mathrm{mV} ; n=13)$. On average, d-ADF amounted to $135 \pm 14 \%$ of the control $(n=13$, Wilcoxon test, $P<0.01$; Fig. $1 \mathrm{~A}$ and B), thus revealing a facilitation factor of $1.2 \%$ per $\mathrm{mV}$ of depolarization. d-ADF was not related to the amplitude of the response, the paired-pulse ratio (PPR) or the latency (Supporting Information Fig. S1). Induction of d-ADF was also associated with an increased probability of neurotransmitter release revealed by a reduced PPR (from $111 \pm 5 \%$ at $-77 \mathrm{mV}$ to $92 \pm 8 \%$ at $-48 \mathrm{mV}, n=13$; Fig. $1 \mathrm{C}$ and D) and a reduced rate of synaptic failures (Fig. 1E and F). Altogether, these data support the hypothesis that $\mathrm{d}-\mathrm{ADF}$ at CA3-CA3 excitatory connection results from an increase in glutamate release.

\section{$d-A D F$ requires $K v 1.1$ channels}

Next we examined whether d-ADF requires Kv1.1 channels. At constant presynaptic membrane potential $(-65 \mathrm{mV}), \mathrm{DTx}-\mathrm{K}$, a blocker of Kv1.1 channels, increased synaptic strength to $122 \pm 7 \%$ of the control EPSP/C amplitude ( $n=16$ CA3-CA3 connections; data not shown). We next tested whether d-ADF depended on inactivation of Kv1.1 channels at CA3-CA3 synaptic contacts. In fact, DTx-K occluded ADF (from $116 \pm 5$ to $83 \pm 9 \%, n=7$, Wilcoxon test, $P<0.01$; Fig. 2A and B). No synaptic facilitation was observed upon depolarization, suggesting that $\mathrm{d}-\mathrm{ADF}$ requires inactivation of Kv1.1 channels.

\section{$d$-ADF at CA3-CA3 synapses is time-dependent}

The D-type current generated by Kv1.1 channels has an inactivation time constant of $\sim 3 \mathrm{~s}$ (Storm, 1988; Kole et al., 2007; Cudmore et al., 2010). We therefore examined whether the time course of d-ADF was compatible with the inactivation kinetics of $I_{\mathrm{D}}$. The presynaptic neuron was depolarized to potentials just subthreshold for AP firing $(\sim-45 \mathrm{mV})$ and APs were elicited by additional, brief current injections $0.2,3.2,6.2$ or $9.2 \mathrm{~s}$ after depolarization onset. Supporting the implication of the slow inactivating D-type current, transmission was facilitated with a time constant of $\sim 3.7 \mathrm{~s}$ (Fig. $2 \mathrm{C}$ and D).

Next, we examined whether d-ADF was also time-dependent with physiological depolarization such as theta oscillations. Episodes of subthreshold $\theta$ oscillations $(\sim 10 \mathrm{mV} ; 8 \mathrm{~Hz}, 2$ or $10 \mathrm{~s})$ were applied to the presynaptic cell by injection of sinusoidal current. Synaptic facilitation was larger if the oscillations were long lasting $(2 \mathrm{~s}$ : $100 \pm 3 \%, n=11$; Wilcoxon test, $P>0.1 ; 10 \mathrm{~s}: 108 \pm 3 \%$ $n=11$, Wilcoxon $P<0.05$; Fig. $2 \mathrm{E}$ and F). We conclude that $\mathrm{d}-$ $\mathrm{ADF}$ is not only voltage-dependent but also time-dependent. 
A

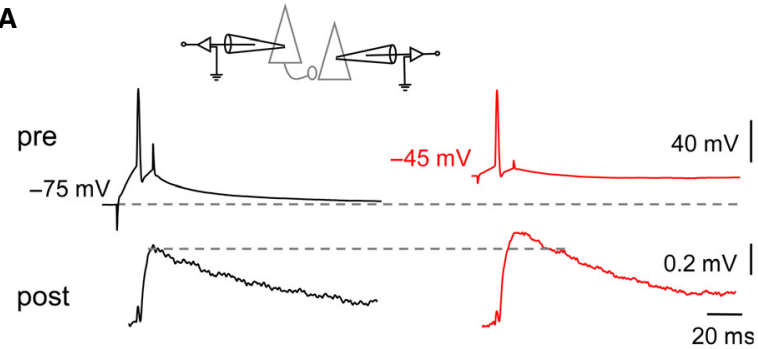

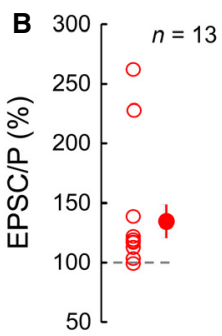

C
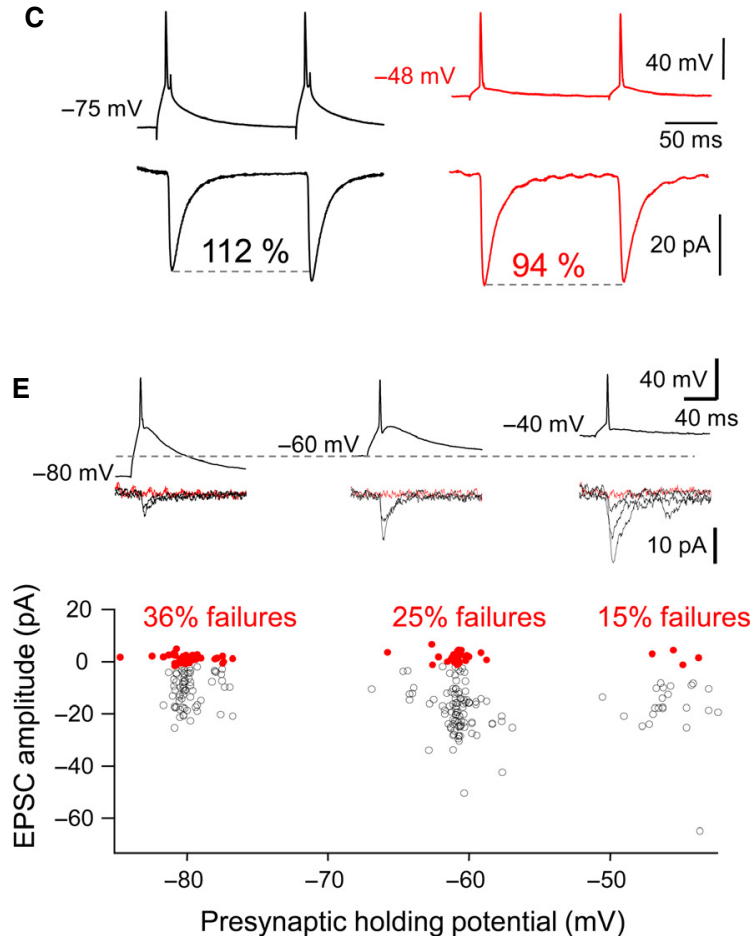

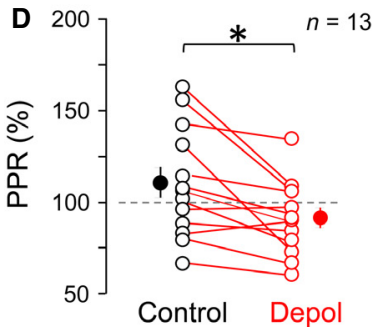

Control Depol

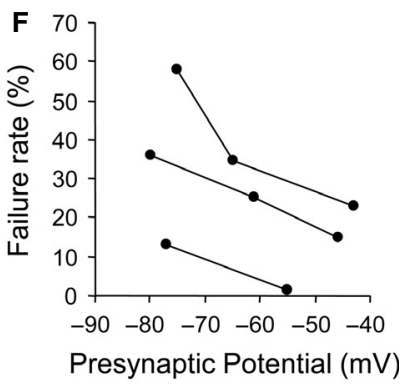

FIG. 1. Depolarization-induced analog-digital facilitation (d-ADF) of synaptic transmission at CA3-CA3 connections. (A) Example of d-ADF at an excitatory CA3-CA3 synaptic contact. Average EPSP traces (bottom) evoked by APs triggered from control (black traces) and depolarized potentials (red traces). (B) Summary of d-ADF quantified by the normalized EPSC amplitude measured in single cells (open circles). (C) Change in paired-pulse ratio (PPR) after induction of d-ADF (interstimulus interval $=150 \mathrm{~ms}$ ). Note the reduction in PPR (from 112 to $94 \%$ in this example). (D) Pooled data $\left({ }^{*} P<0.005\right.$, Wilcoxon test). (E) Reduction in synaptic failures after d-ADF. Paired recording from two connected CA3-CA3 pyramidal neurons. Presynaptic AP triggered from a potential of $-80 \mathrm{mV}$ evoked small postsynaptic currents (black traces) with a high proportion of synaptic failures (36\%). At resting membrane potential ( $-60 \mathrm{mV})$, the failure rate decreased to $25 \%$. When the holding potential is maintained at $-50 \mathrm{mV}$, synaptic transmission increased and the failure rate further decreased $(15 \%)$. (F) Plot of the failure rate as function of the holding potential of the presynaptic neuron.

\section{$d-A D F$ is associated with spike broadening in the axon}

In neocortical and hippocampal axons, spike width and subsequently synaptic transmission are controlled by Kv1 channels (Kole et al., 2007; Boudkkazi et al., 2011). Thus, the enhanced spike-evoked transmission observed at depolarized potential may result from the broadening of the presynaptic spike. We first examined this issue using voltage imaging of single CA3 neurons. The axon was identified as the only neuronal process devoid of spines in which a significant rise in $\mathrm{Na}^{+}$could be detected (Supporting Information Fig. S2; see also Methods). For voltage imaging, neurons were filled with JPW3028 (250 $\mu$ m; Fig. 3A). The depolarization of the cell body from -70 to $-50 \mathrm{mV}$ (Fig. 3B) broadened the AP measured in the axon [half-width: from $2.2 \pm 0.2$ to $3.4 \pm 0.3 \mathrm{~ms}(+1.2 \mathrm{~ms}), n=5$; Fig. 3C]. No change occurred in adjacent dendrites [from $3.4 \pm 0.3$ to $3.2 \pm 0.1 \mathrm{~ms}(-0.2 \mathrm{~ms}), n=5$; Fig. $3 \mathrm{D}$ ] or in the soma [from $2.5 \pm 0.3$ to $2.9 \pm 0.4 \mathrm{~ms}(+0.4 \mathrm{~ms}), n=5$ ] following depolarization. Interestingly, in the presence of DTx-K (100 nm), the spike was already broader at hyperpolarized potential and no further broadening could be induced by somatic depolarization (from $3.5 \pm 0.4$ to $2.9 \pm 0.2 \mathrm{~ms}, n=3$; Fig. $3 \mathrm{E}$ ). No change occurred in adjacent dendrites following depolarization in the presence of DTxK (Supporting Information Fig. S3). To further confirm these results and to measure change in spike waveform further than the AIS, simultaneous recordings were obtained from the soma in whole-cell configuration and from the axon in cell-attached configuration (70$120 \mu \mathrm{m}$ from the soma; Fig. 3F). Somatic depolarization broadened the AP measured extracellularly in the axon (Fig. 3G-I). In conclusion, somatic depolarization broadens the AP in the axon through inactivation of Kv1.1 channels.

\section{$d-A D F$ is associated with enhanced spike-evoked calcium signals}

We measured how subthreshold and suprathreshold $\mathrm{Ca}^{2+}$ signals were altered in the periterminal region by depolarization of the cell 
A
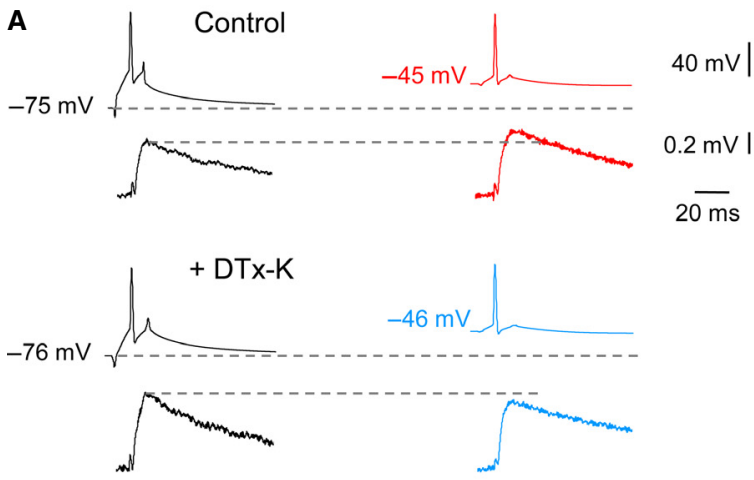

C
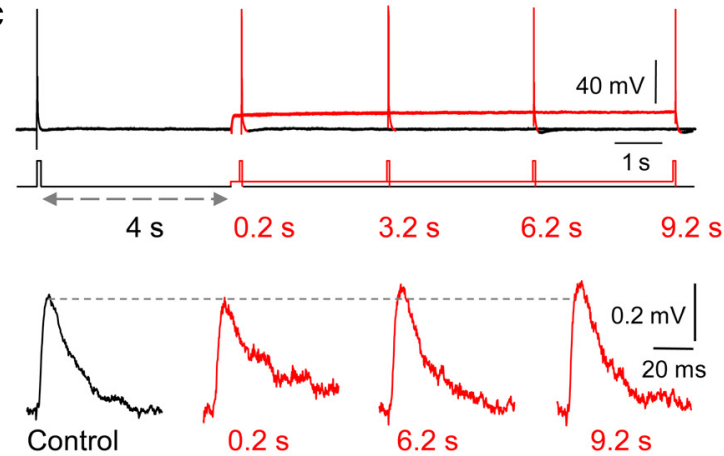

$\mathbf{E}$

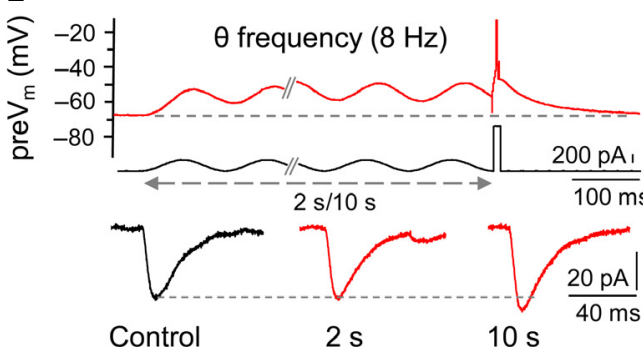

B ODTX-K

O DTX-I
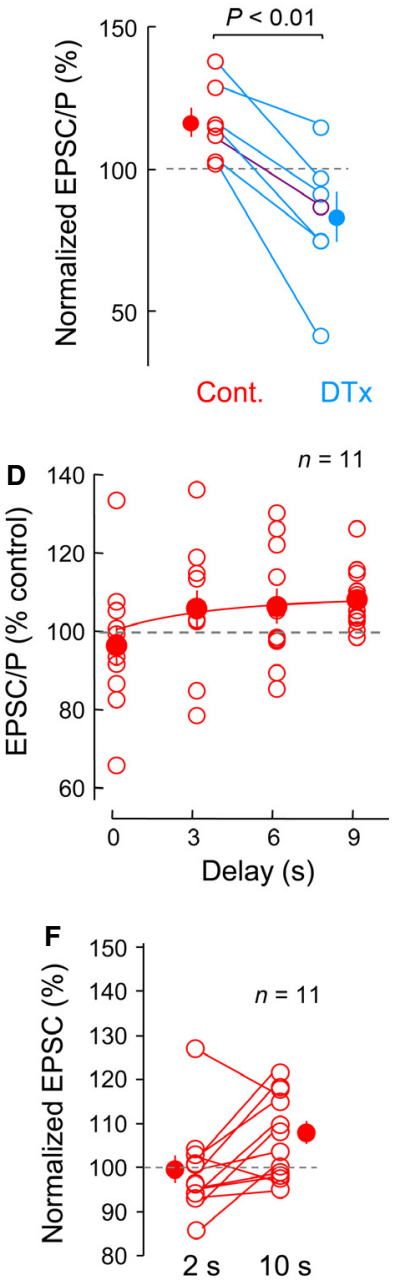

FIG. 2. d-ADF is time-dependent and requires activation of Kv1.1 channels. (A) Top, d-ADF in control conditions. Note the increase in EPSP amplitude when the presynaptic spike is evoked at $-45 \mathrm{mV}$. Bottom, in the presence of DTx-K, the amplitude of the EPSP/C is increased and $\mathrm{d}$-ADF is suppressed. To maintain the presynaptic membrane potential at $-65 \mathrm{mV}$ after application of DTx-K, a small negative current was injected $(-6 \pm 2 \mathrm{pA}, n=7)$. (B) Combined DTxI (a specific blocker of Kv1.1, Kv1.2 and Kv1.6 subunits) and DTx-K occlusion experiments. Note the reduced transmission in DTx and the lack of d-ADF. Time course of d-ADF. (C) Top, experimental design. Control APs (black) were evoked from the resting membrane potential. After a delay of 4 s, the presynaptic neuron was depolarized to $\sim-45 /-50 \mathrm{mV}$ and single APs were evoked with a delay of $0.2,3.2,6.2$ and $9.2 \mathrm{~s}$. Bottom, average traces of EPSPs evoked in different conditions (control in black and test in red). Note the increase in synaptic strength for long delays (6.2 and 9.2 s). (D) Summary of d-ADF time course. Data from single neurons are symbolized by open circles and averages by filled circles. Red line, exponential fit $[f(t)=100+A(1-\exp (-t / \tau)$ with $A=8.26$ and $\tau=3.69]$. Induction of d-ADF by physiological oscillations. (E) Subthreshold $\theta$ oscillations induce d-ADF in CA3 circuits. Left, synaptic transmission was tested in the absence or in the presence of subthreshold oscillation at $8 \mathrm{~Hz}(\theta)$ injected with sinusoidal current for 2 or 10 s. (F) Summary of d-ADF induced by $\theta$ oscillation. Note the facilitation with current for $10 \mathrm{~s}$ but not for $2 \mathrm{~s}$.

body. Basal $\mathrm{Ca}^{2+}$ signals measured with Fluo-4 or Oregon Green BAPTA-1 were enhanced by subthreshold depolarization from -75 to $-55 \mathrm{mV}(+20 \mathrm{mV})$ in the proximal region of the axon but not distally (Fig. 4A). In fact, the space constant $(\lambda)$ of the facilitation in basal $\mathrm{Ca}^{2+}$ concentration was $113 \mu \mathrm{m}$ (Fig. 4A). These $\mathrm{Ca}^{2+}$ signals were greatly reduced by the P/Q-type $\mathrm{Ca}^{2+}$ channel blocker $\omega$ agatoxin IVA ( $39 \pm 12 \%$ of the control amplitude, $n=4$; Fig. 4B), indicating that the subthreshold somatic depolarization opens P/Qtype channels. The first putative en passant bouton on the axon was found at $143 \pm 5 \mu \mathrm{m}(n=25)$ from the cell body (i.e. within the area CA3). This suggests that modulation of basal $\mathrm{Ca}^{2+}$ concentration may contribute to d-ADF only in the proximal part of the axon. In contrast, spike-evoked $\mathrm{Ca}^{2+}$ transients were enhanced by subthreshold depolarization with little attenuation over $300 \mu \mathrm{m}$ (Fig. 4C and D). On average, the facilitation in the peak $\mathrm{Ca}^{2+}$ signal amounted to $+14 \pm 5 \%(n=13$; Wilcoxon, $P<0.05)$. The difference in the spatial extent of the modulation of subthreshold and suprathreshold $\mathrm{Ca}^{2+}$ signals can be easily explained by the nature of the channels and the voltage stimulus (AP or subthreshold depolarization) involved in each case. In fact, a model (see Methods for details) shows that activation of P/Q-type calcium currents by subthreshold depolarization of the soma strongly attenuates along the axon, whereas inactivation of D-type $\mathrm{K}^{+}$currents controlling spike broadening and spike-evoked calcium transients displays very little attenuation along the same portion of the axon (Fig. 4E). We conclude that presynaptic $\mathrm{Ca}^{2+}$ operates in two ways. Basal $\mathrm{Ca}^{2+}$ concentration is elevated solely in the proximal part of the axon $(<150 \mu \mathrm{m})$ by subthreshold depolarization while spike-evoked calcium transients are enhanced by analog depolarization of the soma with very little attenuation over the first $300 \mu \mathrm{m}$. 

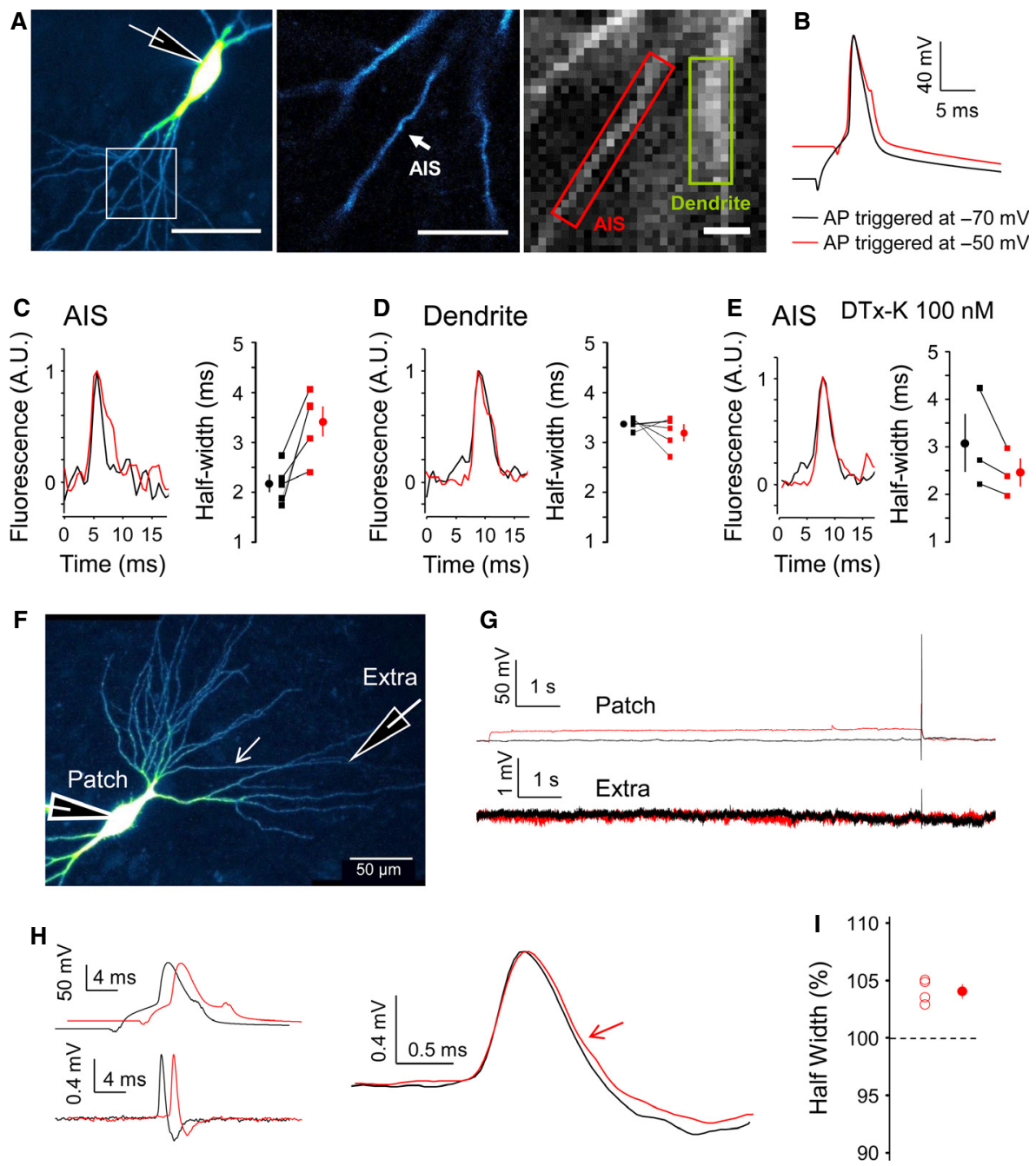

FIG. 3. d-ADF is associated with a broadening of axonal spike due to Kv1.1 inactivation. Voltage imaging of axonal spike during induction of d-ADF. (A) Left, CA3 pyramidal cell filled with Alexa 488 and JPW3028. Middle, magnification of the basal pole of the neuron. Right, fluorescence image obtained following excitation of JPW3028. Red rectangle, AIS; green rectangle, basal dendrite. Scale bars $=50,20$ and $5 \mu \mathrm{m}$. (B) Electrophysiological recording from the soma of the same neuron. (C) Left, comparison of the AP waveform in the AIS when the spike is triggered from a constant holding potential of $-70 \mathrm{mV}$ (black) or $-50 \mathrm{mV}$ (red). Note the broadening of the spike. Right, group data. (D) Left, comparison of the AP waveform in the dendrite. Right, group data. Note the lack of effect induced by the depolarization. (E) Lack of effect in the presence of DTx-K (see also Supporting Information Fig. S3). Left, comparison of the AP waveform in the AIS when the spike is triggered from a constant holding potential of $-70 \mathrm{mV}$ (black) or $-50 \mathrm{mV}$ (red) in DTx-K extracellular solution. Note the larger half-width at $-70 \mathrm{mV}$ in the presence of DTx-K compared with control (C). Right, group data. (F-I) d-ADF increases spike width recorded extracellularly in the axon. (F) Confocal image of a CA3 neuron filled with Alexa 488. The axon trunk (white arrow) is recorded in cell-attached configuration. (G) Simultaneous recordings from the soma (top) and axon (bottom) when the spike is triggered from resting membrane potential (black traces) or from a 10-s depolarizing pre-pulse (red traces). (H) Comparison of the spike shape recorded intracellularly (upper left traces) and extracellularly (bottom left traces). Right, close-up of the extracellular AP recorded in the axon, showing an increase in spike width upon depolarization (red arrow). (I) Quantitative analysis of the depolarization-induced enhancement of the axonal spike $(104 \pm 0.5 \%, n=4)$.

\section{EGTA prevents both $d-A D F$ and the modulation of spike- evoked $\mathrm{Ca}^{2+}$ transients}

Next, we tested the role of slow modulation of $\mathrm{Ca}^{2+}$ concentration with the calcium chelator EGTA $(10 \mathrm{~mm})$ in the pipette. Synaptic transmission was measured during alternative episodes of hyperpolarization and steady-state depolarization. d-ADF was blocked when the presynaptic pipette contained 10 mm EGTA (Fig. 5A; $84 \pm 9 \%$ of the control EPSP/C amplitude, $n=9$; significantly different from control, Mann-Whitney $U$-test $P<0.01$ ). These data therefore confirm that $\mathrm{d}-\mathrm{ADF}$ is calcium-dependent. At this concentration, EGTA is supposed to clamp basal intracellular $\mathrm{Ca}^{2+}$ concentration but it could also affect the voltage-dependent modulation of spike-evoked calcium transient in the presynaptic terminal. In fact, compared with the control situation ( $0.5 \mathrm{~mm}$ EGTA) the amplitude of spike-evoked transients was markedly reduced with $10 \mathrm{~mm}$ EGTA (from $88 \pm 29 \% \Delta F / F$ in $0.5 \mathrm{~mm}$ EGTA to $31 \pm 8 \% \Delta F / F, n=7$ in 10 mM EGTA; Fig. 5B). In addition, voltage shifts from -70 to $-50 \mathrm{mV}$ produced no significant increase in the $\mathrm{Ca}^{2+}$ transient evoked by the spike when the neuron was recorded with $10 \mathrm{~mm}$ EGTA $(101 \pm 7 \%, n=7$; Wilcoxon $P>0.5$; Fig. 5C). We conclude that the preventing voltage-dependent modulation of the spike-evoked $\mathrm{Ca}^{2+}$ transient in the presynaptic terminal also prevents induction of $\mathrm{d}-\mathrm{ADF}$ in $\mathrm{CA} 3$ neurons.

\section{Modeling of $d-A D F$}

We next examined whether d-ADF could be modeled in a compartmental Hodgkin-Huxley-type model (see Methods). To mimic 


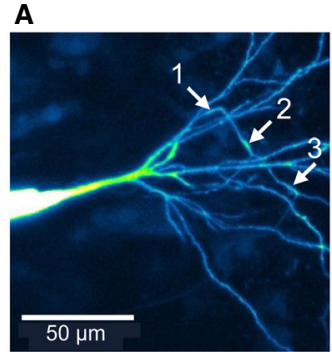

B

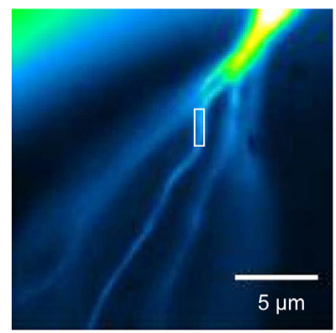

c
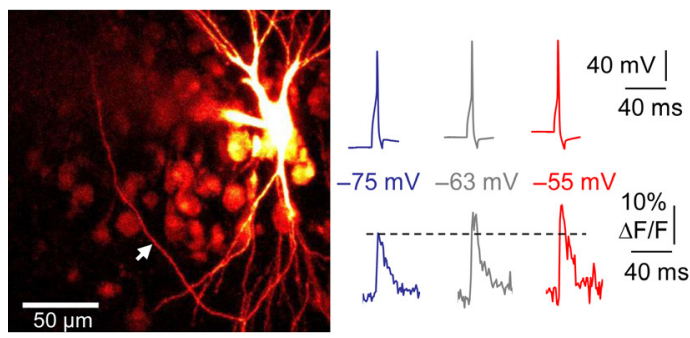
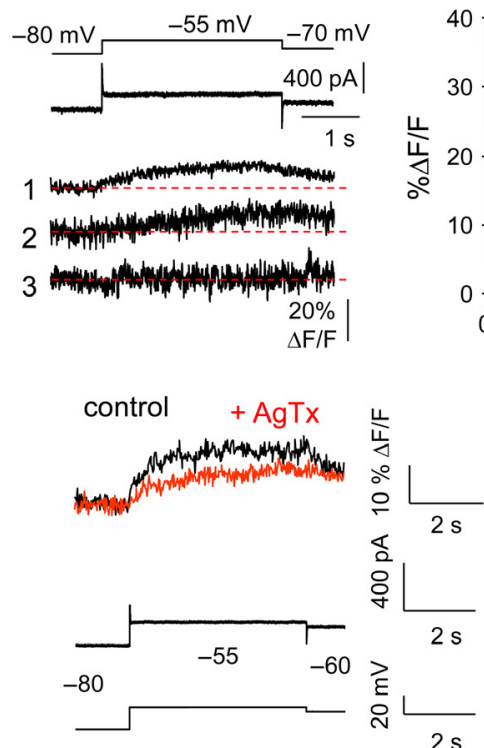
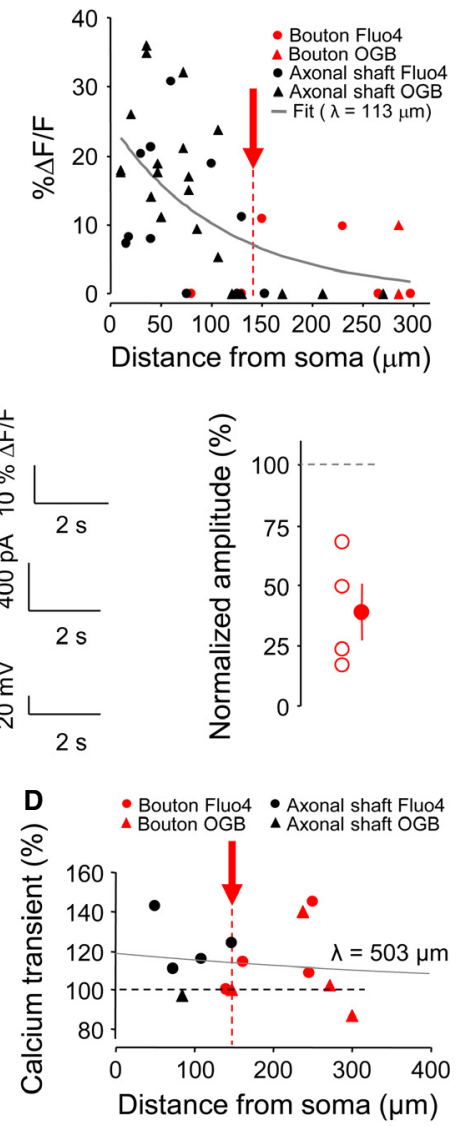

E Model
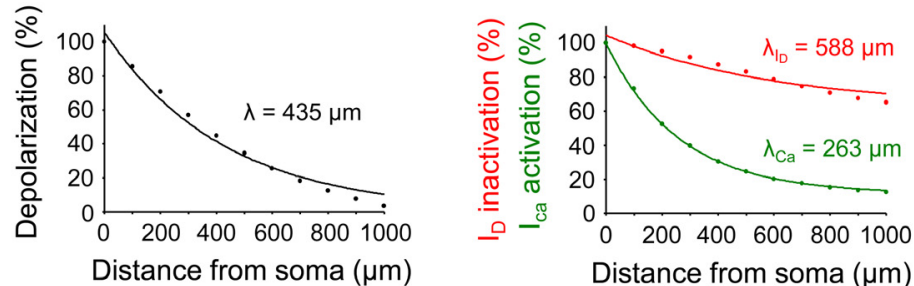

FIG. 4. d-ADF is associated with elevated spike-evoked $\mathrm{Ca}^{2+}$ transients in CA3 axons. (A) Modulation of basal Ca ${ }^{2+}$ by subthreshold depolarization. Left, confocal image of a CA3 neuron loaded with OGB-1 and recorded in voltage clamp. Three regions of interest (1-3) were studied along the axon (arrows). Middle, calcium signals evoked by depolarization from -80 to $-55 \mathrm{mV}$. Note the lack of signal in the distal part (3). Right, plot of the variation of fluorescence caused by the subthreshold depolarization as a function of the distance from soma. Gray line, exponential fit $\left(y=A \mathrm{e}^{(-x / \lambda)}+C\right.$; with $A=22.4, \lambda=113 \mu \mathrm{m}$ and

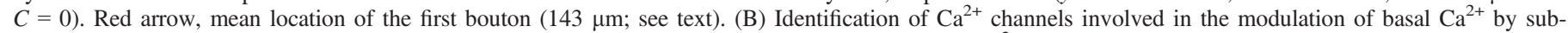
threshold depolarization and spatial spread of voltage signals along the axon. Sensitivity of axonal Ca ${ }^{2+}$ concentration changes to $\omega$-agatoxin-IVA (AgTx). Left, details of the region of interest (white rectangle) on the AIS of a CA3 pyramidal neuron recorded with a pipette containing OGB-1. Middle, the P/Q-type channel blocker AgTx reduces calcium signal measured in the AIS and evoked by subthreshold depolarization from -80 to -55 mV. Right, group data showing the inhibition of the $\mathrm{Ca}^{2+}$ signal by AgTx. (C) Modulation of spike-evoked $\mathrm{Ca}^{2+}$ transients in the axon (250 $\mu \mathrm{m}$ from the soma). Left, confocal image of the recorded neuron loaded with Alexa-594 and Fluo-4. Right, $\mathrm{Ca}^{2+}$ transients evoked by APs elicited from -75 , -65 and $-55 \mathrm{mV}$. Note the facilitation in the $\mathrm{Ca}^{2+}$ signal when the spike is triggered from a depolarized potential (red traces). (D) Plot of the normalized fluorescence increase as a function of the distance from the soma. Gray line, exponential fit $\left(y=A e^{(-x / \lambda)}+C\right.$; with $A=19, C=100$ and $\left.\lambda=503 \mu \mathrm{m}\right)$. Red arrow, mean location of the first bouton (143 $\mu$ m). (E) Modeling study of the spatial spread of voltage along the axon and modulation of P/Q- and D-type currents. Left, decay of voltage along the axon. At $1000 \mu \mathrm{m}$ only $3.5 \%$ of the depolarization imposed (to $-55 \mathrm{mV}$ ) in the soma remains. The space constant of the axon is thus $435 \mu \mathrm{m}$. Right, spatial spread of activation of P/Q-type $\mathrm{Ca}^{2+}$ (green) and D-type (red) currents activated by the voltage profile shown in the left column. The space constant for the P/Q-type calcium current was $263 \mu \mathrm{m}$ and for the D-type current was $588 \mu \mathrm{m}$.

d-ADF, the presynaptic soma was constantly depolarized to $-55 \mathrm{mV}$. The spike waveform and the $\mathrm{Ca}^{2+}$ current $\left(I_{\mathrm{Ca}}\right)$ were measured in the terminal, $200 \mu \mathrm{m}$ away. The EPSP was measured in the soma of a postsynaptic cell. The depolarization increased the spike half-width in the terminal to $141 \%$ of the control (Fig. 6A), enhanced the charge of the presynaptic spike-evoked $\mathrm{Ca}^{2+}$ current mediated by the opening of P/Q-type calcium channels (125\% the control charge) and subsequently increased synaptic strength (116\%; Fig. 6A).

Next, we tested whether the increased synaptic transmission observed upon pharmacological blockade of Kv1 channels could be reproduced in the model. The suppression of Kv1 channels in the axon produced an increase in spike half-width (164\%; Fig. 6B), which resulted in an elevation in spike-evoked $\mathrm{Ca}^{2+}$ current 


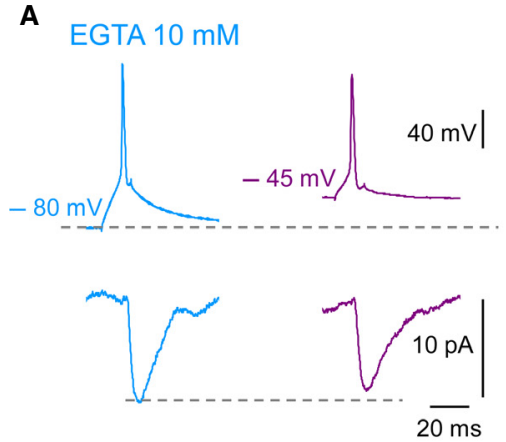

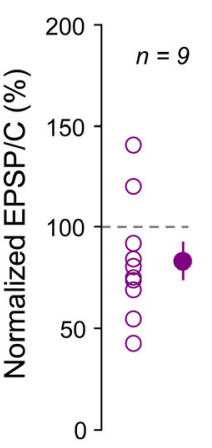

C

EGTA $0.5 \mathrm{mM}$

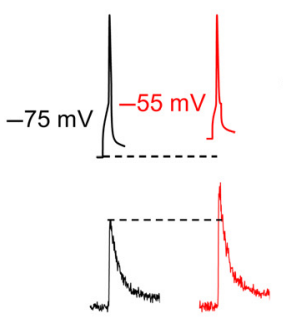

EGTA $10 \mathrm{mM}$

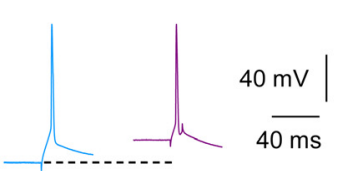

$\Delta \overline{\mathrm{F} / \mathrm{F}}$

$\frac{40 \mathrm{mV}}{40 \mathrm{~ms}}$

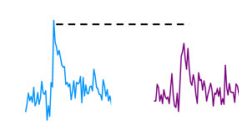

B

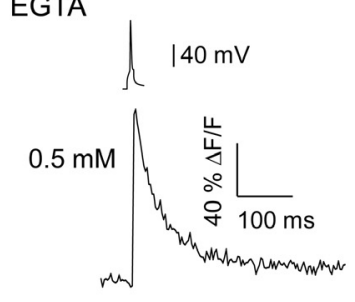

$10 \mathrm{mM}$

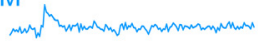

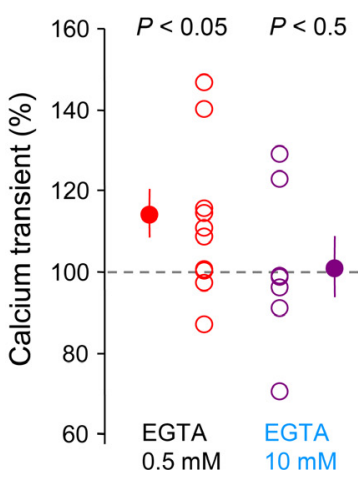

FIG. 5. EGTA prevents both d-ADF and the modulation of spike-evoked $\mathrm{Ca}^{2+}$ transient. (A) lLack of d-ADF in the presence of 10 mm EGTA in the presynaptic recording pipette. Left, representative example. Right, pooled data. (B) Reduction of spike-evoked calcium transient in 10 mm EGTA. Data were measured with OGB-1. (C) Spike-evoked calcium transients are facilitated by somatic depolarization in recordings with 0.5 mm EGTA but not with 10 mm EGTA. Left, representative records with 0.5 or $10 \mathrm{~mm}$ EGTA. Right, quantitative data.

A

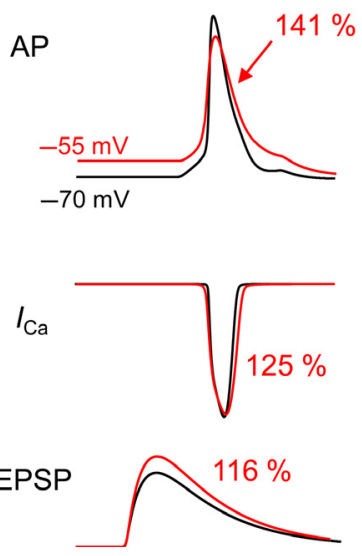

B With $I_{D}$ Without $I_{\mathrm{D}}$
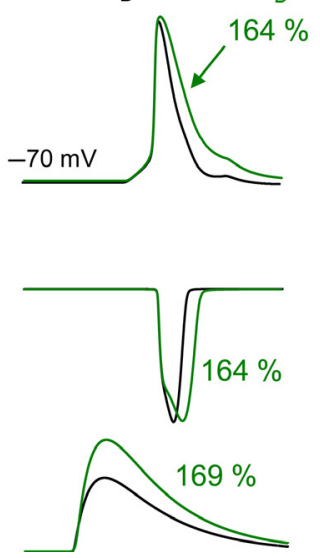

C No inactivating $I_{D}$
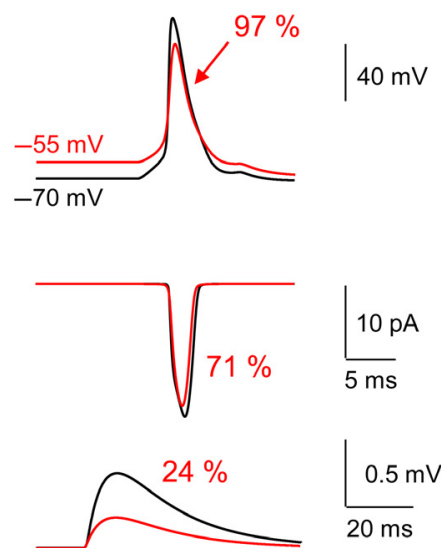

FIG. 6. Modeling of the depolarization-induced facilitation of release. (A) Membrane potential and $\mathrm{Ca}^{2+} \mathrm{current}$ were measured in the terminal (200 $\mu \mathrm{m}$ from the soma) of the presynaptic modeled cell and EPSPs in the postsynaptic modeled cell. The depolarization of the presynaptic soma causes an increase in the spike-evoked $\mathrm{Ca}^{2+}$ charge measured in the bouton and enhanced the amplitude of the EPSP. (B) Modeling of the DTx-induced facilitation of release. The suppression of $I_{\mathrm{D}}$ (green traces) increased spike duration, enhanced spike-evoked $\mathrm{Ca}^{2+}$ transient and increased EPSP amplitude. Note the spike broadening and the increase in presynaptic $\mathrm{Ca}^{2+}$ current. (C) Modeling of the voltage-induced changes in AP waveform with non-inactivating $I_{\mathrm{D}}$. Comparison of the spike-evoked $\mathrm{Ca}^{2+}$ current at rest $(-70 \mathrm{mV}$, black traces $)$ and when the soma is depolarized $\left(-55 \mathrm{mV}\right.$, red traces). Note the reduction of both the Ca ${ }^{2+}$ charge and the EPSP amplitude.

measured at the terminal (164\% of the control charge) and synaptic strength (169\%; Fig. 6B). Moreover, d-ADF is totally dependent on D-type current inactivation as both the $\mathrm{Ca}^{2+}$ charge and synaptic transmission were found to be decreased upon constant depolarization of the cell when inactivation of the D-type current was suppressed $(71 \%$ of the control charge and $24 \%$ of EPSP amplitude; Fig. 6C). In conclusion, our model demonstrates that d-ADF observed experimentally is entirely explained by the modulation of spike-evoked presynaptic $\mathrm{Ca}^{2+}$ signals.

\section{Discussion}

Using a combination of electrophysiological, imaging and computer simulation techniques, we show here that d-ADF at CA3-CA3 
synapses is not only voltage-dependent but also time-dependent. dADF is induced by long (5-10 s) presynaptic depolarizations such as subthreshold theta oscillations. It is mediated by an increase in presynaptic glutamate release, as shown by both the reduced PPR and the reduced rate of synaptic failures. d-ADF is associated with spike broadening in the axon and enhanced spike-evoked $\mathrm{Ca}^{2+}$ transient in the terminal, but not with elevation in basal $\mathrm{Ca}^{2+}$ produced by the opening of voltage-gated $\mathrm{Ca}^{2+}$ channels. Both d-ADF and AP broadening in the axon are prevented by the specific Kv1.1 channel blocker DTx-K. Thus, d-ADF results from the Kv1.1-dependent enhancement of spike-evoked $\mathrm{Ca}^{2+}$ in the presynaptic boutons, in a time-dependent manner.

\section{Time-dependence of $d$-ADF in CA3 neuron}

AD facilitation produced by somatic depolarization has been reported at CA3-CA3 connections (Sasaki et al., 2012). However, the kinetics of facilitation was not addressed in this study. Rather, the spike broadening measured in the axon was found to depend purely on voltage, suggesting that d-ADF in CA3 neurons would be time-independent. In fact, our data clearly show that d-ADF in CA3 neurons is time-dependent. No facilitation occurs with brief presynaptic depolarization such as current-induced depolarization for $0.2 \mathrm{~s}$ (Fig. 2C and D) or $\theta$ oscillations for $2 \mathrm{~s}$ (Fig. 2E and F). The timedependence of d-ADF may result from two possible mechanisms: the slow kinetics of the D-type current found in these neurons (Cudmore et al., 2010) or the slow kinetics of basal $\mathrm{Ca}^{2+}$ elevation in the axon (see Fig. 4A and B). The fact that d-ADF is blocked by DTx-K, a specific blocker of Kv1.1 channels, indicates that the slow time-course of d-ADF results from the D-type current generated by Kv1.1 channels. In fact, the time-constant of the inactivation kinetics of the D-type current at $-40 \mathrm{mV}$ is in the seconds range (Kole et al., 2007). The slow time-course of d-ADF is unlikely to result from the slow kinetics of basal $\mathrm{Ca}^{2+}$ elevation in the axon. The basal $\mathrm{Ca}^{2+}$ signal declines rapidly along the axon and the boutons located beyond $140 \mu \mathrm{m}$ are virtually not affected by this calcium rise (Fig. 4). In contrast, the enhancement of the spike-evoked $\mathrm{Ca}^{2+}$ transient mediated by inactivation of the D-type current declines more slowly along the axon and significantly affects presynaptic boutons (Fig. 4).

\section{d-ADF in CA3 neurons is mediated by Kv1.1 channels}

We show here that d-ADF is totally blocked in the presence of DTx-K, a specific Kv1.1 channel blocker. Furthermore, using voltage imaging, we show that sustained depolarization of the cell body considerably lengthens spike duration in the proximal part of the axon. This effect was abolished if Kv1.1 channels were blocked by DTx-K. Our measurements were restricted to the proximal part of the axon because the CA3 axon is rarely in a single focal plane and the diffusion of the voltage-sensitive dye JPW3028 is limiting in distal regions of the axon. However, extracellular recordings obtained from more distal axonal regions (70-120 $\mu \mathrm{m}$ from the soma) indicate that the spike is also broader, as observed previously (Sasaki et al., 2012). In the cortex, d-ADF was prevented by DTx-I (Kole et al., 2007), a non-specific toxin that blocks Kv1.1, Kv1.2 and Kv1.6 channels. Our study provides a more precise conclusion by showing that specifically blocking Kv1.1 prevents the induction of $\mathrm{d}-\mathrm{ADF}$ in CA3 neurons.

Our data indicate that d-ADF is produced by the D-type currentdependent increase in the spike-evoked $\mathrm{Ca}^{2+}$ transient. Other $\mathrm{Kv}$ channels such as TEA-sensitive Kv3 channels are present in presyn- aptic terminals of GABAergic interneurons (Goldberg et al., 2005, 2008; Rowan et al., 2014) or granule cells (Alle et al., 2011), and control synaptic transmission. However, these channels are unlikely to play a critical role in the mechanism of d-ADF in CA3 pyramidal neurons. First, all the facilitation was suppressed by the selective Kv1.1 channel blocker DTx-K. In addition, the depolarizationinduced broadening of the AP in the axon is suppressed by DTx-K. Finally, Kv3 channels have not been reported to modulate synaptic transmission in pyramidal neurons. In contrast to 4-aminopyridine, TEA has very little effect on excitatory synaptic transmission in hippocampal (Schwartzkroin \& Prince, 1980; Huang \& Malenka, 1993) and neocortical pyramidal neurons (Boudkkazi et al., 2011).

d-ADF was found to vary across connections. Although no correlation was seen between d-ADF and EPSP/C amplitude, latency or PPR (Supporting Information Fig. S1), we cannot exclude that axonal path length and heterogeneity of Kv1 density in presynaptic boutons and along the axon may account for the observed variability in d-ADF. In fact, in layer 5 pyramidal neurons, the magnitude of d$\mathrm{ADF}$ is inversely proportional to the axonal path length (Kole et al., 2007). In addition, freeze-fracture replica immunogold labeling reveals variability in the number of $\mathrm{Kv} 1$ channels per presynaptic bouton (Kirizs et al., 2014).

\section{The role of basal and spike-evoked $\mathrm{Ca}^{2+}$ signals in d-ADF}

Our study clarifies the relative contribution of basal $\mathrm{Ca}^{2+}$ and spikeevoked $\mathrm{Ca}^{2+}$ transients. We show that while basal $\mathrm{Ca}^{2+}$ is enhanced in the axon with a space constant of $\sim 110 \mu \mathrm{m}$, facilitation of the spike-evoked $\mathrm{Ca}^{2+}$ signal displays little attenuation over the first $300 \mu \mathrm{m}$. The difference between these two types of measurement can be easily explained by the voltage-sensitivity of the ion channels involved. In fact, the $\mathrm{Ca}^{2+}$ influx produced by subthreshold depolarization results from the opening of high-threshold P/Q-type $\mathrm{Ca}^{2+}$ channels in the axon, as observed previously in neocortical and cerebellar axons (Yu et al., 2010; Bouhours et al., 2011; Christie et al., 2011). The attenuation of depolarization along the axon will limit activation of these channels to the proximal part of the axon. In contrast, the low-threshold D-type current that determines the spike duration in the axon is extremely sensitive to small changes in voltage. Inactivation of $I_{\mathrm{D}}$ can be strongly modulated by small depolarization between the resting membrane potential and the spike threshold. Thus, our model indicates that at $500 \mu \mathrm{m}$ from the soma, the same axonal depolarization will have a negligible effect on $\mathrm{P} /$ Q-type $\mathrm{Ca}^{2+}$ channels but a much larger effect on Kv1.1 channels (see Fig. 4E). In addition, $10 \mathrm{~mm}$ EGTA was found to prevent both the induction of d-ADF and the modulation of spike-evoked $\mathrm{Ca}^{2+}$ transients induced by somatic depolarization. This further suggests that d-ADF results from modulation of spike-evoked $\mathrm{Ca}^{2+}$ transients by inactivation of $I_{\mathrm{D}}$.

These measurements were obtained from both axon collaterals and putative en passant boutons. The first putative en passant boutons were observed at a distance of $143 \mu \mathrm{m}$ from the soma. These boutons were visualized within area CA3 and are therefore likely to correspond to local connections between pyramidal cells. Pyramidal cells indeed represent the great majority of neurons in area CA3.

Although we cannot totally exclude the possibility that very small elevations in basal $\mathrm{Ca}^{2+}$ concentration may also favor synaptic enhancement observed upon presynaptic depolarization, especially because $\mathrm{Ca}^{2+}$ ions activate the release sensor with high cooperativity (Scott et al., 2008), the contribution of basal $\mathrm{Ca}^{2+}$ to d-ADF in CA3 neurons is probably very minor because all the facilitation was blocked by DTx-K. Furthermore, blocking voltage-induced 
modulation of spike-evoked calcium transients with 10 mM EGTA also prevented d-ADF. Thus, all the experimental manipulations that blocked the modulation of spike-evoked $\mathrm{Ca}^{2+}$ transients also prevented d-ADF. Finally, a simple model containing five currents $\left(I_{\text {Nasoma }}, I_{\text {Naaxon }}, I_{\mathrm{KDR}}, I_{\mathrm{D}}\right.$ and $\left.I_{\mathrm{CaP} / \mathrm{Q}}\right)$ showed that the spike-evoked presynaptic $\mathrm{Ca}^{2+}$ current is increased when the somatic compartment is persistently depolarized as in $\mathrm{ADF}$ experiments.

In conclusion, our study clarifies the mechanisms by which the informational content of spikes is regulated by activity in the CA3 area. Additional experimental work will be needed to determine whether d-ADF can be observed in hippocampal neurons in vivo, and how the generalization of d-ADF to a large population of CA3 pyramidal neurons affects the dynamics of the hippocampal network.

\section{Supporting Information}

Additional supporting information can be found in the online version of this article:

Fig. S1. d-ADF is not correlated with EPSP/C amplitude, PPR or EPSP/C Latency.

Fig. S2. Identification of the axon of CA3 pyramidal neurons.

Fig. S3. Voltage imaging of CA3 neurons in the presence of DTx-K.

\section{Acknowledgements}

This study was supported by the Institut National de la Santé et de la Recherche Médicale, Université Aix-Marseille, Centre National de la Recherche Scientifique, Agence Nationale de la Recherche (ANR 11 BSV4 016 01), Fondation pour le Recherche Médicale (doctoral grant to A.B. and postdoctoral grant to V.M.), the French Ministry of Research (doctoral grant to A.B.), and the Ecole Normale Supérieure (doctoral grant to M.Z.). We thank L. Loew for the gift of JPW3028, and E. Neher, M. Seagar and I. Segev for helpful discussion and comments on the manuscript.

\section{Abbreviations}

$\mathrm{AD}$, analog-digital; AIS, axon initial segment; AP, action potential; CNS, central nervous system; d-ADF, depolarization-induced AD facilitation; EPSC, excitatory post-synaptic current; EPSP, excitatory post-synaptic potential; PPR, paired pulse ratio.

\section{References}

Alle, H. \& Geiger, J.R. (2006) Combined analog and action potential coding in hippocampal mossy fibers. Science, 311, 1290-1293.

Alle, H., Kubota, H. \& Geiger, J.R. (2011) Sparse but highly efficient Kv3 outpace BKCa channels in action potential repolarization at hippocampal mossy fiber boutons. J. Neurosci., 31, 8001-8012.

Awatramani, G.B., Price, G.D. \& Trussell, L.O. (2005) Modulation of transmitter release by presynaptic resting potential and background calcium levels. Neuron, 48, 109-121.

Bischofberger, J., Geiger, J.R. \& Jonas, P. (2002) Timing and efficacy of $\mathrm{Ca}^{2+}$ channel activation in hippocampal mossy fiber boutons. J. Neurosci., 22, 10593-10602.

Boudkkazi, S., Carlier, E., Ankri, N., Caillard, O., Giraud, P., Fronzaroli-Molinieres, L. \& Debanne, D. (2007) Release-dependent variations in synaptic latency: a putative code for short- and long-term synaptic dynamics. Neuron, 56, 1048-1060.

Boudkkazi, S., Fronzaroli-Molinieres, L. \& Debanne, D. (2011) Presynaptic action potential waveform determines cortical synaptic latency. J. Physiol.London, 589, 1117-1131.

Bouhours, B., Trigo, F.F. \& Marty, A. (2011) Somatic depolarization enhances GABA release in cerebellar interneurons via a calcium/protein kinase C pathway. J. Neurosci., 31, 5804-5815.

Christie, J.M., Chiu, D.N. \& Jahr, C.E. (2011) $\mathrm{Ca}^{2}{ }^{+}$-dependent enhancement of release by subthreshold somatic depolarization. Nat. Neurosci., 14, 62-68.
Cudmore, R.H., Fronzaroli-Molinieres, L., Giraud, P. \& Debanne, D. (2010) Spike-time precision and network synchrony are controlled by the homeostatic regulation of the D-type potassium current. J. Neurosci., 30, 1288512895.

Debanne, D., Boudkkazi, S., Campanac, E., Cudmore, R.H., Giraud, P., Fronzaroli-Molinieres, L., Carlier, E. \& Caillard, O. (2008) Paired-recordings from synaptically coupled cortical and hippocampal neurons in acute and cultured brain slices. Nat. Protoc., 3, 1559-1568.

Debanne, D., Bialowas, A. \& Rama, S. (2013) What are the mechanisms for analogue and digital signalling in the brain? Nat. Rev. Neurosci., 14, 6369.

Destexhe, A., Mainen, Z.F. \& Sejnowski, T.J. (1994) Synthesis of models for excitable membranes, synaptic transmission and neuromodulation using a common kinetic formalism. J. Comput. Neurosci., 1, 195-230.

Foust, A.J., Yu, Y., Popovic, M., Zecevic, D. \& McCormick, D.A. (2011) Somatic membrane potential and Kv1 channels control spike repolarization in cortical axon collaterals and presynaptic boutons. J. Neurosci., 31, 15490-15498.

Goldberg, E.M., Watanabe, S., Chang, S.Y., Joho, R.H., Huang, Z.J., Leonard, C.S. \& Rudy, B. (2005) Specific functions of synaptically localized potassium channels in synaptic transmission at the neocortical GABAergic fast-spiking cell synapse. J. Neurosci., 25, 5230-5235.

Goldberg, E.M., Clark, B.D., Zagha, E., Nahmani, M., Erisir, A. \& Rudy, B. (2008) $\mathrm{K}^{+}$channels at the axon initial segment dampen near-threshold excitability of neocortical fast-spiking GABAergic interneurons. Neuron, $\mathbf{5 8}, 387-400$.

Hu, W., Tian, C., Li, T., Yang, M., Hou, H. \& Shu, Y. (2009) Distinct contributions of $\mathrm{Na}_{\mathrm{v}} 1.6$ and $\mathrm{Na}_{\mathrm{v}} 1.2$ in action potential initiation and backpropagation. Nat. Neurosci., 12, 996-1002.

Huang, Y.Y. \& Malenka, R.C. (1993) Examination of TEA-induced synaptic enhancement in area CA1 of the hippocampus: the role of voltage-dependent $\mathrm{Ca}^{2+}$ channels in the induction of LTP. J. Neurosci., 13, $568-576$.

Kim, S., Guzman, S.J., Hu, H. \& Jonas, P. (2012) Active dendrites support efficient initiation of dendritic spikes in hippocampal CA3 pyramidal neurons. Nat. Neurosci., 15, 600-606.

Kirizs, T., Kerti-Szigeti, K., Lorincz, A. \& Nusser, Z. (2014) Distinct axo-somato-dendritic distributions of three potassium channels in CA1 hippocampal pyramidal cells. Eur. J. Neurosci., 39, 1771-1783.

Kole, M.H., Letzkus, J.J. \& Stuart, G.J. (2007) Axon initial segment Kv1 channels control axonal action potential waveform and synaptic efficacy. Neuron, 55, 633-647.

Lazarewicz, M.T., Migliore, M. \& Ascoli, G.A. (2002) A new bursting model of CA3 pyramidal cell physiology suggests multiple locations for spike initiation. Biosystems, 67, 129-137.

Major, G., Larkman, A.U., Jonas, P., Sakmann, B. \& Jack, J.J. (1994) Detailed passive cable models of whole-cell recorded CA3 pyramidal neurons in rat hippocampal slices. J. Neurosci., 14, 4613-4638.

Meeks, J.P. \& Mennerick, S. (2007) Action potential initiation and propagation in CA3 pyramidal axons. J. Neurophysiol., 97, 3460-3472.

Nicholls, J. \& Wallace, B.G. (1978) Modulation of transmission at an inhibitory synapse in the central nervous system of the leech. J. Physiol.-London, 281, 157-170.

Rowan, M.J., Tranquil, E. \& Christie, J.M. (2014) Distinct kv channel subtypes contribute to differences in spike signaling properties in the axon initial segment and presynaptic boutons of cerebellar interneurons. J. Neurosci., 34, 6611-6623.

Sasaki, T., Matsuki, N. \& Ikegaya, Y. (2012) Effects of axonal topology on the somatic modulation of synaptic outputs. J. Neurosci., 32, 2868-2876.

Saviane, C., Mohajerani, M.H. \& Cherubini, E. (2003) An ID-like current that is downregulated by $\mathrm{Ca}^{2+}$ modulates information coding at CA3CA3 synapses in the rat hippocampus. J. Physiol.-London, 552, 513524.

Schwartzkroin, P.A. \& Prince, D.A. (1980) Effects of TEA on hippocampal neurons. Brain Res., 185, 169-181.

Scott, R., Ruiz, A., Henneberger, C., Kullmann, D.M. \& Rusakov, D.A. (2008) Analog modulation of mossy fiber transmission is uncoupled from changes in presynaptic $\mathrm{Ca}^{2+}$. J. Neurosci., 28, 7765-7773.

Seil, F.J., Drake-Baumann, R., Herndon, R.M. \& Leiman, A.L. (1992) Cytosine arabinoside effects in mouse cerebellar cultures in the presence of astrocytes. Neuroscience, 51, 149-158.

Shapiro, E., Castellucci, V.F. \& Kandel, E.R. (1980) Presynaptic membrane potential affects transmitter release in an identified neuron in Aplysia by modulating the $\mathrm{Ca}^{2+}$ and $\mathrm{K}^{+}$currents. Proc. Natl. Acad. Sci. USA, 77, $629-633$. 
Shepherd, G.M., Raastad, M. \& Andersen, P. (2002) General and variable features of varicosity spacing along unmyelinated axons in the hippocampus and cerebellum. Proc. Natl. Acad. Sci. USA, 99, 63406345.

Shimahara, T. \& Peretz, B. (1978) Soma potential of an interneurone controls transmitter release in a monosynaptic pathway in Aplysia. Nature, 273, 158-160

Shimahara, T. \& Tauc, L. (1975) Multiple interneuronal afferents to the giant cells in Aplysia. J. Physiol.-London, 247, 299-319.

Shu, Y., Hasenstaub, A., Duque, A., Yu, Y. \& McCormick, D.A. (2006) Modulation of intracortical synaptic potentials by presynaptic somatic membrane potential. Nature, 441, 761-765

Shu, Y., Duque, A., Yu, Y., Haider, B. \& McCormick, D.A. (2007a) Properties of action-potential initiation in neocortical pyramidal cells: evidence from whole cell axon recordings. J. Neurophysiol., 97, 746-760.
Shu, Y., Yu, Y., Yang, J. \& McCormick, D.A. (2007b) Selective control of cortical axonal spikes by a slowly inactivating $\mathrm{K}^{+}$current. Proc. Natl. Acad. Sci. USA, 104, 11453-11458.

Storm, J.F. (1988) Temporal integration by a slowly inactivating $\mathrm{K}^{+}$current in hippocampal neurons. Nature, 336, 379-381.

Yang, J., Ye, M., Tian, C., Yang, M., Wang, Y. \& Shu, Y. (2013) Dopaminergic modulation of axonal potassium channels and action potential waveform in pyramidal neurons of prefrontal cortex. J. Physiol.-London, 591, 3233-3251.

Yu, Y., Maureira, C., Liu, X. \& McCormick, D. (2010) P/Q and N channels control baseline and spike-triggered calcium levels in neocortical axons and synaptic boutons. J. Neurosci., 30, 11858-11869.

Zhu, J., Jiang, M., Yang, M., Hou, H. \& Shu, Y. (2011) Membrane potential-dependent modulation of recurrent inhibition in rat neocortex. PLoS Biol., 9, e1001032. 